\title{
An experimental study of Ti-6Al-4V powder reactivity in gaseous environment: Application to additive manufacturing
}

\author{
Mohamad Mahdi Siblani ${ }^{1}$, Maelig Ollivier ${ }^{1}$, Loïc Favergeon ${ }^{1}$ \\ ${ }^{1}$ Mines Saint-Etienne, Univ Lyon, CNRS, UMR 5307 LGF, Centre SPIN, F-42023, Saint-Etienne, France
}

\begin{abstract}
Currently, one of the current issues related to the additive manufacturing is the change in the properties of Ti-6Al-4V powder during this process. This change has been attributed to the interaction of this powder with its gaseous environment that can contain a small quantity of oxygen, nitrogen, carbon dioxide and/or water vapour. Therefore, the aim of this work is to study the effect of oxygen and nitrogen partial pressure as well as the effect of the temperature on the corrosion of the Ti-6Al-4V powder. The results show that the temperature and the oxygen partial pressure have an effect on the corrosion kinetics, which is not the case of nitrogen partial pressure. This study is a first step towards a better understanding of the ageing of Ti-6Al-4V powder during additive manufacturing processes.
\end{abstract}

\section{Introduction}

Additive manufacturing is considered a promising technology for the design of complex metallic pieces, in a rather short timeframe. Various technologies have been developed based on this concept: for instance, Selective Laser Melting (SLM), Electron Beam Melting (EBM) or Direct Metal Deposition (DMD) are the main three technologies deployed in industry. All these techniques are based on the local melting of previously deposited metallic powder under inert atmosphere. Among the various alloys already available for additive manufacturing, Ti-6Al-4V is one of the most used materials due to its numerous applications in industry -aeronautics and biomedical- and its associated high cost of manufacturing and long lead time[1]. However, it is important to notice that in the additive manufacturing processes, only a small amount of powder is actually used for the final piece and it has been observed that the chemical and rheological properties of the reused powder differ from those of the initial one. These changes are associated with the interaction of the powder with the gaseous environment (corrosion, humidity) in combination with the thermal gradient starting from the melting powder (higher than $1600^{\circ} \mathrm{C}$ ) to the chamber room. The kinetics of the corrosion of Ti-6Al-4V alloy has been extensively studied in the literature for the bulk material, especially regarding high temperature oxidation [2-14]. For instance, H.L. Du et al. [4] observed the formation of a multi-layered oxide structure, that consists of rutile $\mathrm{TiO}_{2}$ (inner layer) and corundum $\mathrm{Al}_{2} \mathrm{O}_{3}$ (outer layer). The number of layers within this oxide structure increases proportionally with the increase of temperature and time. Furthermore, the authors presented a mechanism of formation of the multi-layered oxide scale based on the activity of the elements existing in Ti-6Al-4V alloy. This mechanism can be summarized as follows: after the growth of the first duplex $\mathrm{TiO}_{2} / \mathrm{Al}_{2} \mathrm{O}_{3}$ scale, the difference between the molar volume of $\mathrm{TiO}_{2}$ oxide and Ti- $\alpha$ (Pilling \& Bedworth ratio=1.81) leads to compressive stress inside the scale, resulting in cracks at the metal/oxide interface. Similar results were reported by S. Frangini et al. [5] who observed a transition in the oxidation kinetics from a parabolic to a linear behavior with increasing temperature and time. The authors assume that this transition is due to a change in the morphology of the oxide scale. Additionally, F. Pitt \& M. Ramulu [11] reported that the microstructure, specifically the grain size of the Ti-6Al$4 \mathrm{~V}$ alloy, can play an important role in the oxidation kinetics. In contrast, E. Dong et al. [6] showed that the oxide scale is made of an outer layer of $\mathrm{Al}_{2} \mathrm{O}_{3}$ and $\mathrm{TiO}_{2}$ and an inner multilayer containing $\mathrm{TiO}_{2}$ and $\mathrm{TiVO}_{4}$. On the other hand, few work has been dedicated so far to the study the corrosion and ageing of Ti-6Al-4V powder and the effect of the grain geometry which can play an important role in the corrosion kinetics [15],[16]. For example, in the case of a rate-determining step at the internal interface (between the metallic and oxide phases) and if the oxide layer grows inwards, the surface area of the internal interface and thus the reaction rate will decrease with the reaction conversion for spherical particles. For bulk material (plate-like geometry), the surface area of the internal interface remains constant and the reaction rate does not change with time (for a rate-determining step at the internal interface and in isothermal and isobaric conditions). Moreover, M.M. Arafat et al. [16] found an absence of cracks during high temperature oxidation of Ti-6Al-4V spherical particles with a diameter smaller than $20 \mu \mathrm{m}$, what they explained by the absence of pores accumulation at the metal/oxide interface. For these reasons, there is a growing interest to understand the oxidation of Ti- $6 \mathrm{Al}-4 \mathrm{~V}$ powders that takes into consideration both the geometry and the dimensions of the powders. Therefore, the main goal of the present investigation is to study the behavior of Ti-6Al-4V powder during high temperature corrosion in the temperature range $600-750^{\circ} \mathrm{C}$, partially simulating the temperature gradient affecting the unused powder during additive manufacturing. For the oxidizing gaz, and in order to better understand the corrosion kinetics for this powder, the amount of oxidation found in this work does not represent at all the actual finding during additive manufacturing. The effect of oxygen and nitrogen partial pressure as well as the nature of the oxide scale formed on the Ti-6Al-4V powder will be discussed.

\section{Materials \& Methods}

Ti-6Al-4V powder manufactured by the TLS company has been used for this study. The powder is obtained by a plasma atomization process under argon, leading to nearly perfect spherical grains with diameter ranging from 10 to $60 \mu \mathrm{m}$, in accordance with the safety data sheet provided by the manufacturer. The chemical composition of the alloy has been measured by inductively coupled plasma-optical emission spectrometry (ICP-OES. Model Activa from Horiba Jobin-Yvon). 
Table 1: Chemical composition of Ti-6Al-4V powder from TLS

\begin{tabular}{|cccccccccc|}
\hline & $\mathbf{T i}$ & Al & V & Fe & O & N & H & C & Y \\
\hline wt. \% & balance & 6,36 & 4,06 & 0,22 & 0,11 & 0,007 & 0,0026 & 0,015 & $<0,001$ \\
\hline
\end{tabular}

The study of the corrosion kinetics of Ti-6Al-4V powder as a function of temperature as well as oxygen and nitrogen partial pressures have been carried out using thermogravimetry analysis with a symmetrical thermobalance TAG24 from SETARAM (which allows a direct compensation of Archimedes' buoyancy and thermohydraulic effects). This apparatus allows monitoring the mass change during the high temperature corrosion experiments. The experimental procedure can be detailed as follows: to avoid the mass and heat transfer, approx. $15 \mathrm{mg}$ of Ti-6Al-4V powder is weighted into an alumina crucible placed inside the furnace. Once closed this latter is pumped down with a rotary pump for $30 \mathrm{~min}$ then filled with commercial helium until reaching atmospheric pressure $\left(10^{5} \mathrm{hPa}\right)$. The furnace is then flushed with helium for $30 \mathrm{~min}$ before the heating ramp of $10^{\circ} \mathrm{C} / \mathrm{min}$. Once the targeted temperature is reached, a mixture of helium and a corroding gas with a controlled partial pressure is injected at a flowing rate of $4 \mathrm{~L} / \mathrm{h}$. The temperature and gas partial pressures are kept constant for 5 hours. The time $\mathrm{t}=0$ (s) of the mass curves presented here corresponds to the beginning of the isothermal and isobaric conditions.

The results of thermogravimetry analysis have been processed as follows. The mass change as a function of time is normalised according to Eq. 1 , where $m_{0}$ represents the initial sample mass and $m_{t}$ the sample mass at a given time.

$\Delta m=\frac{m_{t}-m_{0}}{m_{0}, \text { Eq. } 1}$

The effect of nitrogen and oxygen partial pressures has been studied under $5 \mathrm{hPa}$ and $25 \mathrm{hPa}$ of $\mathrm{N}_{2}$ and 5,15 , and $20 \mathrm{hPa}$ of $\mathrm{O}_{2}$ at $700^{\circ} \mathrm{C}$, respectively. Moreover, the effect of the temperature has been studied at $600,700^{\circ} \mathrm{C}$ and $750^{\circ} \mathrm{C}$ under $15 \mathrm{hPa}$ of $\mathrm{O}_{2}$.

The corroded samples have been characterized with Field-Emission Gun Scanning Electron Microscopy (FEG-SEM) using a Zeiss Supra 55 VP microscope coupled with energy dispersive X-ray spectroscopy (EDX). The Ti-6Al-4V powders are observed either directly or in cross-section. In this latter case the specimen is mounted in a cold resin, then polished using SiC abrasive with grit size ranged from 1000 to 2400 and finally $0.04 \mu \mathrm{m}$ colloidal silica suspension. Afterwards, the mounted samples are ultrasonically cleaned in alcohol and air-dried.

\section{Results and discussion}

The mass change of a Ti-6Al-4V powder sample during a typical high temperature treatment at $700^{\circ} \mathrm{C}$ for 5 hours under helium at atmospheric pressure is presented Figure 1. It is noteworthy that the sample mass increases with time. This mass gain of approximately $5 \%(\Delta \mathrm{m}=0.05)$ of the initial sample mass is explained by the presence of impurities in helium. The helium gas used for this study is actually contaminated by a small amount of impurities which have been quantified: for a total pressure of $1000 \mathrm{hPa}$, a partial pressure of $0.5 \mathrm{hPa}$ of water vapour, $0.1 \mathrm{hPa}$ of oxygen and $0.4 \mathrm{hPa}$ of nitrogen have been determined. Thus, this mass gain is not surprising since the Ti-6Al-4V alloy is well known to highly react at high temperature with nitriding and oxidising species. From this point of view, these impurities should be taken into account regarding the corrosion kinetics. That is why a minimum partial pressure of $\mathrm{O}_{2}$ of $2.5 \mathrm{hPa}$ has been imposed for the whole set of experiments, assuming this gas was the main responsible of the mass gain observed on Figure 1.

The influence of the nitrogen partial pressure on the corrosion kinetics of Ti-6Al-4V is presented Figure 2. The plot of normalized mass change of Ti-6Al-4V samples versus time recorded for a heat treatment carried out at $700^{\circ} \mathrm{C}$ for $5 \mathrm{~h}$ for two different partial pressures of nitrogen, respectively $5 \mathrm{hPa}$ and $25 \mathrm{hPa}$, highlights no evidence of an effect of nitrogen partial pressure in these conditions. One can assume that the mass gain is mainly due to the oxidation of Ti-6Al-4V under the $2.5 \mathrm{hPa}$ partial pressure of $\mathrm{O}_{2}$. 


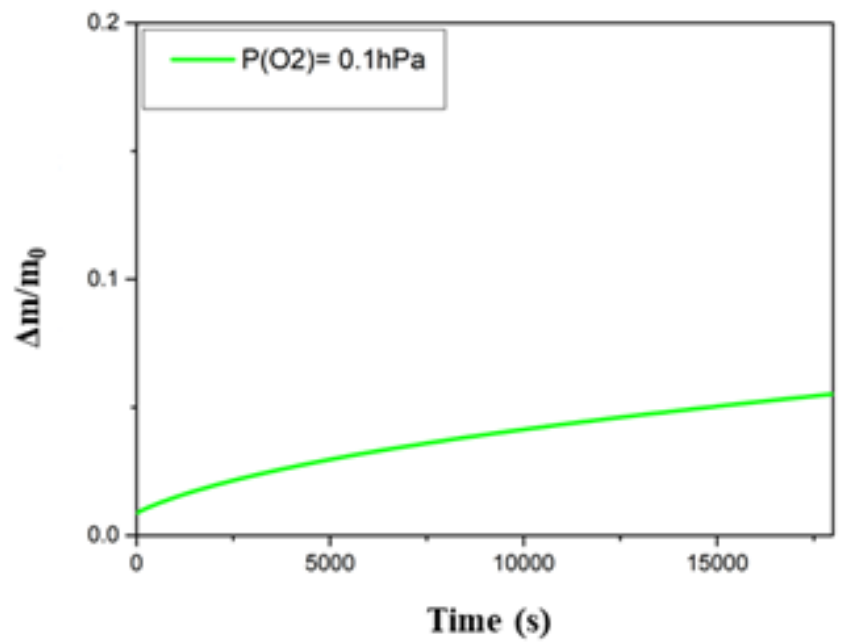

Figure 1: Normalized mass change of Ti-6Al-4V powder heat-treated at $700^{\circ} \mathrm{C}$ under $\mathrm{He}$ with $0.1 \mathrm{hPa}$ of $\mathrm{O}_{2}$.

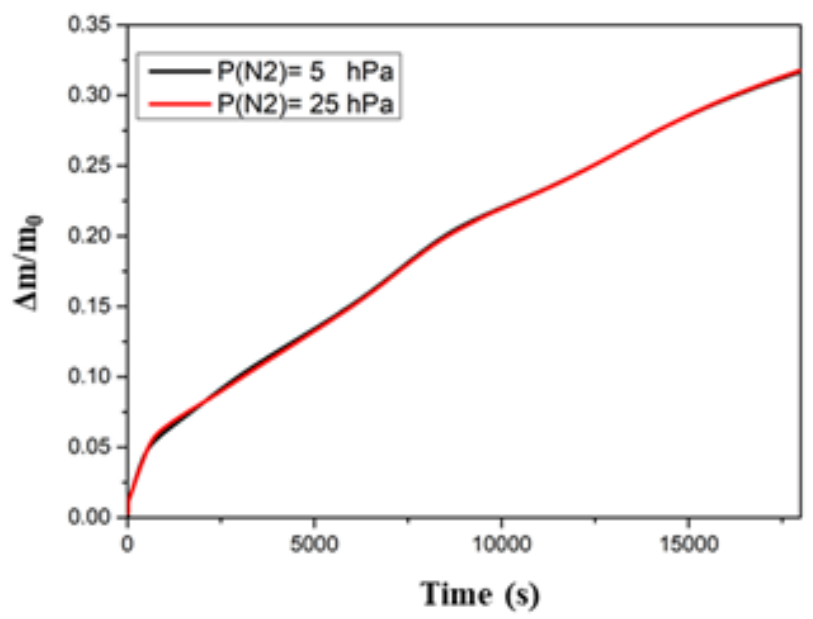

Figure 2: Influence of nitrogen partial pressure on the normalized mass change of Ti-6Al-4V powder during thermal corrosion at $700^{\circ} \mathrm{C}$ under $\mathrm{P}\left(\mathrm{N}_{2}\right)=5 \mathrm{hPa}$ (black line) and $\mathrm{P}\left(\mathrm{N}_{2}\right)=25 \mathrm{hPa}$ (red line), with $\mathrm{P}\left(\mathrm{O}_{2}\right)=2.5 \mathrm{hPa}$ in both experiments.

\section{Effect of oxygen partial pressure}

Figure 3 shows the corrosion tests performed on Ti-6Al-4V powder samples for several oxygen partial pressures $\left(\mathrm{P}\left(\mathrm{O}_{2}\right)=0.1,5,15\right.$ and $20 \mathrm{hPa}$ ) at $700^{\circ} \mathrm{C}$ for $5 \mathrm{~h}$.

First of all, two experiments have been carried out at $\mathrm{P}\left(\mathrm{O}_{2}\right)=5 \mathrm{hPa}$ in order to verify the repeatability of the experiments. As it can be noticed comparing the red \& turquoise curves plotted in Figure 3 , the repeatability of the measurements are very good. Therefore, if the mass gain after $5 \mathrm{~h}$ at $\mathrm{P}\left(\mathrm{O}_{2}\right)=0.1 \mathrm{hPa}$ remains relatively low $(\Delta \mathrm{m}=0.05)$, the values increases with the partial pressure of $\mathrm{O}_{2}$. Indeed, the mass gains after $5 \mathrm{~h}$ are $0.38,0.4$ and 0.42 for partial pressure of $\mathrm{O}_{2}$ equals to 5,15 and $20 \mathrm{hPa}$, respectively. This slight increase in mass gain is not surprising since the different oxygen partial pressure are with a comparable order of magnitude. However, when the magnitude of the oxygen partial pressure was 25 time smaller ( $0.1 \mathrm{hPa})$, a significant effect of oxygen partial pressure is observable. Focusing on the oxidation under $5,15,20 \mathrm{hPa}$, it is clear that the oxygen partial pressure has a negligible effect for the first 3000 seconds ( $\Delta \mathrm{m}=0.15$ for the four corrosion tests). These similar mass gains are probably due to the dissolved oxygen in the Ti-6Al-4V alloy that represents 27 at.\% of the total oxygen amount (after $300 \mathrm{~h}$ under air at $700^{\circ} \mathrm{C}$ ) [5]. Beyond $3000 \mathrm{~s}$, the mass gain increases slightly and proportionally with oxygen partial pressure. According to G. Bertrand et al. [18], this slight increase in mass gain is due to a slight difference in the structure of the oxide scale. In order to better understand the reasons of these results, the different oxide scales are currently under study. 


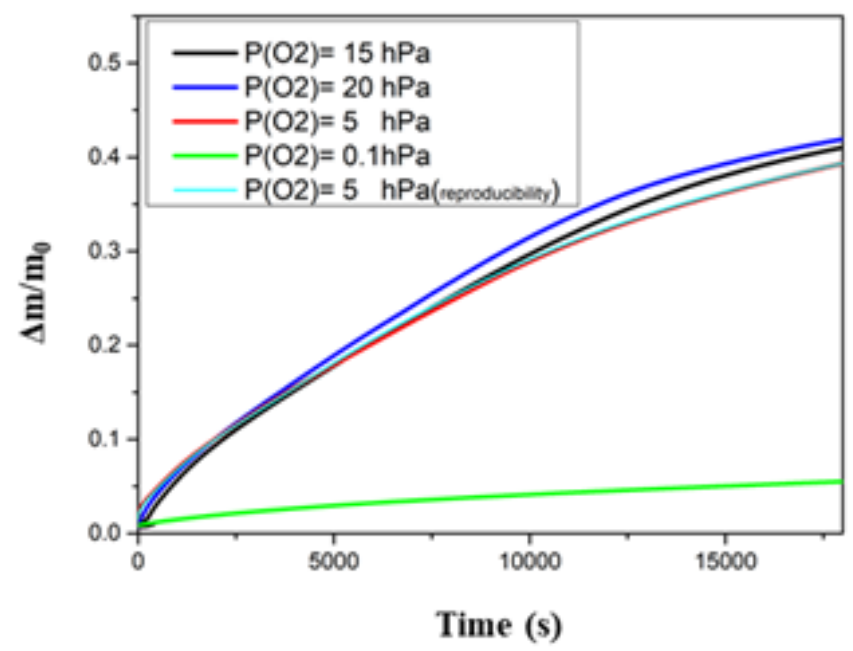

Figure 3: Normalized mass change of Ti-6Al-4V powder samples heat-treated at $700^{\circ} \mathrm{C}$, as a function of time for various oxygen partial pressures.

Effect of the temperature

Figure 4 shows the evolution of the normalized weight gain $(\Delta \mathrm{m})$ versus time at various temperatures for the same partial pressure of $\mathrm{O}_{2}$. It is evident that increasing temperature causes an increasing on the oxidation of the Ti-6Al-4V powder. At $600^{\circ} \mathrm{C}$ the mass gain is very low $(\Delta \mathrm{m}=0.08)$, while at $700^{\circ} \mathrm{C}$ and $750^{\circ} \mathrm{C}$ it is higher $(\Delta \mathrm{m}=0.43$ and 0.58 respectively).

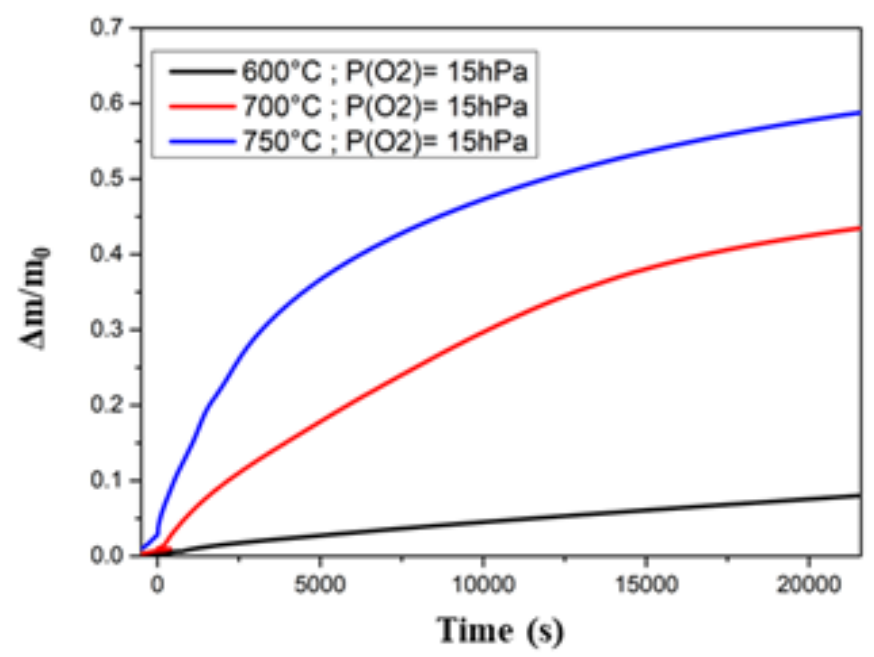

Figure 4: Effect of temperature on the oxidation kinetics of Ti-6Al-4V powder. The oxygen partial pressure is kept constant at $\mathrm{P}\left(\mathrm{O}_{2}\right)=15 \mathrm{hPa}$.

Figure 5 and Figure 6 show the SEM images and corresponding elemental map of the Ti-6Al-4V powder after high temperature oxidation for $5 \mathrm{~h}$ at $600^{\circ} \mathrm{C}$ and $700^{\circ} \mathrm{C}$, respectively. For the corrosion test at $600^{\circ} \mathrm{C}$, a single layer of oxide is visible on the surface of the particles (Figure 5-a). EDS elemental map reveals that this oxide scale consists mainly of Ti and $\mathrm{O}$ (Figure 5 -b \& 5-d). Al is less detected in the oxide scale (Figure $5-c$ ). It is interesting to note that despite the high value of the Pilling \& Bedworth ratio (PBR) between $\mathrm{TiO}_{2}$ and Ti-6Al-4V alloy (PBR=1.81 for Ti- $a$ and PBR=1.74 for Ti- $\beta$ ), cracks are not found in this case. On the other hand, cracks are visible on the metal/oxide interface for the powder oxidized at $700^{\circ} \mathrm{C}$ (see white arrow on Figure 6-a). From the EDS elemental mapping, the presence of $\mathrm{O}$ in the whole scale is evident (Figure 6-d). The detection of Al atoms only in the outer oxide scale (Figure 6-C) suggests that this layer is $\mathrm{Al}_{2} \mathrm{O}_{3}$ whilst Ti atoms detected in the inner oxide scale suggests that this layer is $\mathrm{TiO}_{2}$ (Figure 6-b). According to H.L. Du [4] who studied the oxidation behaviour of Ti-6Al-4V bulk in the range of $650-850^{\circ} \mathrm{C}$ under air, cracks are a result of the limited plasticity of the oxide scale. In addition, C. Coddet and al. [17] reveal that the adherence of the oxides layers is relatively high for temperatures below $650^{\circ} \mathrm{C}$, while it drops sharply at $700^{\circ} \mathrm{C}$. 

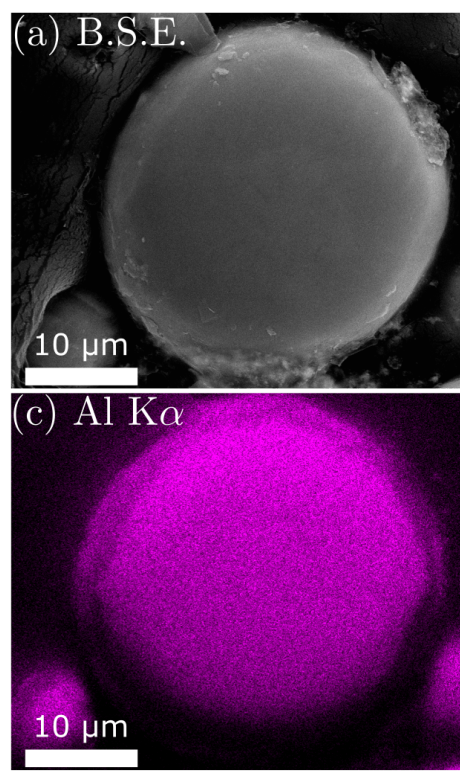
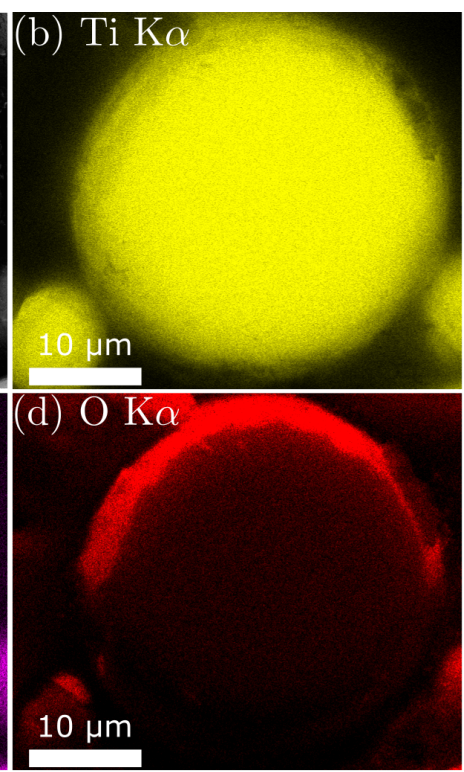

Figure 5: SEM image in back-scattered electron mode (a) and EDX mapping -(b): $\mathrm{Ti},(\mathrm{c}): \mathrm{Al},(\mathrm{d}): \mathrm{O}-\mathrm{of} \mathrm{Ti}-6 \mathrm{Al}-4 \mathrm{~V}$ powder oxidized at $600^{\circ} \mathrm{C}$ for $5 \mathrm{~h}$, with $\mathrm{P}\left(\mathrm{O}_{2}\right)=15 \mathrm{hPa}$.
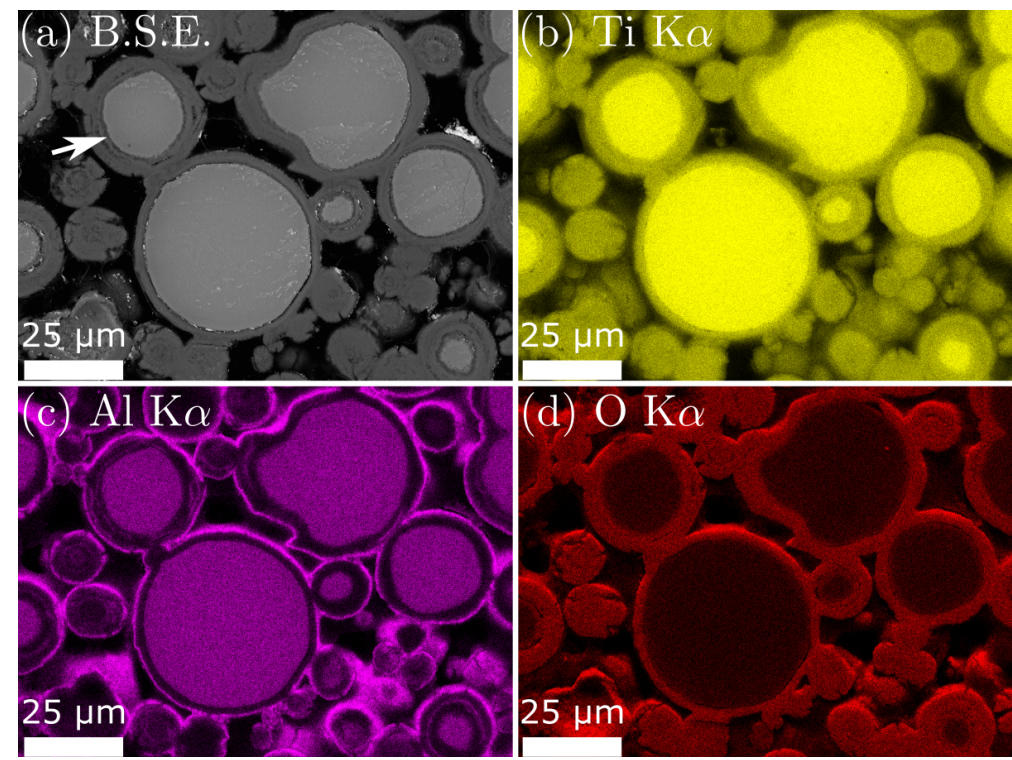

Figure 6: SEM image in back-scattered electron mode (a) and EDX mapping -(b): Ti, (c): Al, (d): 0 - of Ti-6Al-4V powder oxidized at 700 ${ }^{\circ} \mathrm{C}$ for 5 h, with $\mathrm{P}\left(\mathrm{O}_{2}\right)=15 \mathrm{hPa}$.

\section{Conclusion}

This study dealt with the effect of thermodynamic parameters such as temperature and partial pressures of $\mathrm{O}_{2}$ and $\mathrm{N}_{2}$ on the corrosion kinetics of Ti-6Al-4V powders used in additive manufacturing. This experimental study relied on thermogravimetry analyses in isothermal and isobaric conditions. First, the effect of impurities (namely $\mathrm{O}_{2}, \mathrm{~N}_{2}$ and $\mathrm{H}_{2} \mathrm{O}$ ) found in a commercial inert gas has been demonstrated during the heat treatment of Ti-6Al-4V powder. In addition, it has been shown that the variation of nitrogen partial pressure does not influence the corrosion kinetics of Ti-6Al-4V powder heat-treated $5 \mathrm{~h}$ at $700^{\circ} \mathrm{C}$. On the other hand, the partial pressure of oxygen has a direct influence on the mass gain of Ti-6Al-4V powder, just as the temperature of the heat treatment. Based on these first results, the next phase of this project will be to take into account the partial pressure of $\mathrm{H}_{2} \mathrm{O}$, as well as to quantify the corrosion kinetics of Ti-6Al-4V powders as a function of the partial pressures of the different corroding gases, which may be found in an additive manufacturing apparatus.

\section{$\underline{\text { References }}$}

[1] B. Baufeld et O. van der Biest, « Mechanical properties of Ti-6Al-4V specimens produced by shaped metal deposition », Science and Technology of Advanced Materials, vol. 10, $\mathrm{n}^{\mathrm{o}}$ 1, p. 015008, janv. 2009. 
[2] H. Guleryuz et H. Cimenoglu, « Oxidation of Ti-6Al-4V alloy », Journal of Alloys and Compounds, vol. 472, $\mathrm{n}^{\mathrm{o}}$ 1-2, $\mathrm{p}$. 241-246, mars 2009.

[3] M. N. Mungole, N. Singh, et G. N. Mathur, « Oxidation behaviour of Ti6Al4V titanium alloy in oxygen », Materials Science and Technology, vol. 18, $\mathrm{n}^{\mathrm{O}} 1, \mathrm{p} .111-114$, janv. 2002.

[4] H. L. Du, P. K. Datta, D. B. Lewis, et J. S. Burnell-Gray, «Air oxidation behaviour of Ti慨6Al慨4V alloy between 650 and $850^{\circ} »$, Corrosion Science, vol. 36, $\mathrm{n}^{\circ} 4$, p. 631-642, avr. 1994.

[5] S. Frangini, A. Mignone, et F. de Riccardis, « Various aspects of the air oxidation behaviour of a Ti6Al4V alloy at temperatures in the range 600-700 ${ }^{\circ} \mathrm{C} »$, Journal of Materials Science, vol. 29, no 3, p. 714-720, janv. 1994.

[6] E. Dong, W. Yu, Q. Cai, L. Cheng, et J. Shi, « High-Temperature Oxidation Kinetics and Behavior of Ti-6Al-4V Alloy », Oxidation of Metals, vol. 88, nº 5-6, p. 719-732, déc. 2017.

[7] D. A. Brice et al., « Oxidation behavior and microstructural decomposition of Ti-6Al-4V and Ti-6Al-4V-1B sheet », Corrosion Science, vol. 112, p. 338-346, nov. 2016.

[8] P. A. J. Bagot et al., « The effect of oxidation on the subsurface microstructure of a Ti-6Al-4V alloy », Scripta Materialia, vol. 148, p. 24-28, avr. 2018.

[9] F. Borgioli, E. Galvanetto, A. Fossati, et G. Pradelli, « Glow-discharge and furnace treatments of Ti-6Al-4V », Surface and Coatings Technology, vol. 184, nº 2-3, p. 255-262, juin 2004.

[10] S. Kumar, T. S. N. Sankara Narayanan, S. Ganesh Sundara Raman, et S. K. Seshadri, « Thermal oxidation of Ti6A14V alloy: Microstructural and electrochemical characterization », Materials Chemistry and Physics, vol. 119, n 1-2, p. 337-346, janv. 2010.

[11] F. Pitt et M. Ramulu, «Influence of Grain Size and Microstructure on Oxidation Rates in Titanium Alloy Ti-6Al-4V Under Superplastic Forming Conditions », Journal of Materials Engineering and Performance, vol. 13, $n^{0}$ 6, p. 727-734, déc. 2004.

[12] M. Anuwar, R. Jayaganthan, V. K. Tewari, et N. Arivazhagan, « A study on the hot corrosion behavior of Ti-6Al-4V alloy », Materials Letters, vol. 61, nº 7, p. 1483-1488, mars 2007.

[13] M. Renaud et M. Rigaud, «Étude spectrophotométrique des produits formés au cours de l'oxydation superficielle du titane et de l'alliage TA6V », Journal of the Less Common Metals, vol. 32, nº 3, p. 371-378, sept. 1973.

[14] A. Biswas et J. Dutta Majumdar, « Surface characterization and mechanical property evaluation of thermally oxidized Ti6Al-4V », Materials Characterization, vol. 60, nº 6, p. 513-518, juin 2009.

[15] M. Pijolat et L. Favergeon, « Kinetics and Mechanisms of Solid-Gas Reactions », in Handbook of Thermal Analysis and Calorimetry, vol. 6, Elsevier, 2018, p. 173-212.

[16] A. Casadebaigt, J. Hugues, et D. Monceau, « Influence of Microstructure and Surface Roughness on Oxidation Kinetics at 500-600 ${ }^{\circ} \mathrm{C}$ of Ti-6Al-4V Alloy Fabricated by Additive Manufacturing », Oxidation of Metals, vol. 90, n 5-6, p. 633-648, déc. 2018.

[17] G. Bertrand, K. Jarraya, et J. M. Chaix, « Morphology of oxide scales formed on titanium », Oxidation of Metals, vol. 21, no 1-2, p. 1-19, févr. 1984.

[18] C. Coddet, A. M. Craze, et G. Beranger, « Measurements of the adhesion of thermal oxide films: application to the oxidation of titanium », Journal of Materials Science, vol. 22, nº 8, p. 2969-2974, août 1987. 